nal of Experimental Psychology: Learning, Memory, \& Cognition, 14, 298-304.

Hintzman, D. L., \& Block, R. A. (1971). Repetition and memory: Evidence for a multiple-trace hypothesis. Journal of Experimental Psychology, 88, 297-306.

KAUSLER, D. H. (1990). Automaticity of encoding and episodic memory processes. In E. A. Lovelace (Ed.), Aging and cognition: Mental processes, self awareness and interventions (pp. 29-67). Amsterdam: North-Holland.

KAUSLER, D. H. (1991). Experimental psychology, cognition, and human aging. New York: Springer-Verlag.

Kausler, D. H., \& PUCKetT, J. M. (1980). Frequency judgments and correlated cognitive abilities in young and elderly adults. Journal of Gerontology, 35, 376-382.

KaUSler, D. H., \& Wiley, J. (1990). Temporal memory and content memory for actions: Adult age differences in acquisition and retention. Experimental Aging Research, 16, 147-150.

LoFTUs, G. R. (1985). Evaluating forgetting curves. Journal of Experimental Psychology: Learning, Memory, \& Cognition, 11, 397-406. Salthouse, T. A., Kausler, D. H., \& Saults, J. S. (1988). Investigation of student status, background variables, and feasibility of standard tasks in cognitive aging research. Psychology \& Aging, 3, 29-37.

(Manuscript received September 4, 1992.)

\title{
News and Notes from NSF
}

Most proposals to the National Science Foundation for research and related activities in animal learning and behavior are reviewed by the Advisory Panel for Animal Learning and Behavior. Current members of the Panel are Peter D. Balsam (Barnard College), Carol M. Berman (SUNY, Buffalo), Michael D. Breed (University of Colorado), Ruth E. Buskirk (University of Texas), Edmund J. Fantino (University of California, San Diego), Stewart H. Hulse (Johns Hopkins University), Alan C. Kamil (University of Nebraska), Patricia L. Schwagmeyer (University of Oklahoma), Judy A. Stamps (University of California, Davis), George W. Uetz (University of Cincinnati), and Ken Yasukawa (Beloit College).

The Advisory Panel for Animal Learning and Behavior wishes to maintain the highest methodological standards in observational as well as experimental research. Proposals for observational studies of behavior should describe how observers are trained, how interobserver reliability is assessed, and how observer bias is prevented or controlled.

Most proposals with major neurobiological aspects are reviewed by the following Neuroscience Programs. Each Program Director's name appears in parentheses:

\author{
Cognitive, Computational, and Theoretical Neurobiology \\ (Donald H. Edwards) \\ Neural Mechanisms of Behavior (Christiana M. Leonard) \\ Sensory Systems (Christopher J. Platt) \\ Neuroendocrinology (Kathie L. Olsen) \\ Developmental Neuroscience (Steven C. McLoon) \\ Neuronal and Glial Mechanisms (Sanya A. Springfield)
}

As a result of the recent reorganization of Biological, Behavioral, and Social Sciences at NSF, all of the Programs named above are in the Division of Integrative Biology and Neuroscience (IBN), one of four Divisions in the Directorate for Biological Sciences (BIO).

Target dates for submission of proposals to be reviewed by the Advisory Panel for Animal Learning and Behavior have changed. The new target dates are June 15 and December 15 each year. Neuroscience target dates remain January 15 and July 15. Proposals for Minority Research Initiation and Research in Undergraduate Institutions are reviewed by the disciplinary panels on the same schedule as other research proposals.

Such competitions as NSF Graduate Fellowships, Presidential Faculty Fellows, NSF Young Investigators, Research Planning Grants and Career Advancement Awards for Women Scientists, and the Special Competition for Basic Research in Conservation and Restoration Biology have specially.convened panels and annual deadlines for proposal submission.

For more information, call Fred Stollnitz, Program Director for Animal Behavior, at 202-357-7949, or any of the Neuroscience Program Directors at 202-357-7040. The IBN Fax number is 202-357-7846. 